\title{
Association of European Geological Societies
}

\author{
http://www.aegs.de
}

AEGS is the umbrella organisation for national European Geological Societies. It has been granted the status of an Affiliated Organisation of the International Union of Geological Sciences (IUGS).

\begin{abstract}
Aims
The prime purpose of the Association is to strengthen the links between Geological Societies in Europe. This is achieved by periodic meetings of the European Geological Societies (so-called MAEGS), which have taken place throughout Europe since 1975. Membership of the Association is open to all non-governmental societies, institutions and organisations in Europe active nation-wide in the geo-logical sciences, whether covering the entire subject or specialising in one or more of its branches.
\end{abstract}

\section{Meetings}

Meetings of the Association of European Geological Societies (MAEGS) are held in a different European country each time. The scientific theme of each meeting, which is decided by the host organisations, should appeal to a wide section of the geological community. The format is similar, the meeting taking place over 3 or 4 days with keynote addresses and sessions for the oral presentation of scientific papers. Each meeting includes exhibitions, an accompanying programme of field trips, and social activities. Participation is based on individual application.

The current meeting (MAEGS-13) was hold in Hanover (Germany) from 10-13 September 2003 at the Geozentrum (www.geozentrum-hannover.de ). MAEGS-13 was chaired under the direction of Dr. Volker Steinbach, the current vice-president. The theme of the Meeting is a hot topic under European geologists: "Geosciences and the European Water Framework Directive". Over 140 delegates from 30 countries attended the meeting. The purpose of the meeting, explained Dr Volker Steinbach of the German Geological Survey, outgoing AEGS President (picture) was to review the implementation of the WFD in countries across Europe, to promote transnational cooperation between involved geoscientists, and to facilitate communication between geoscientists and

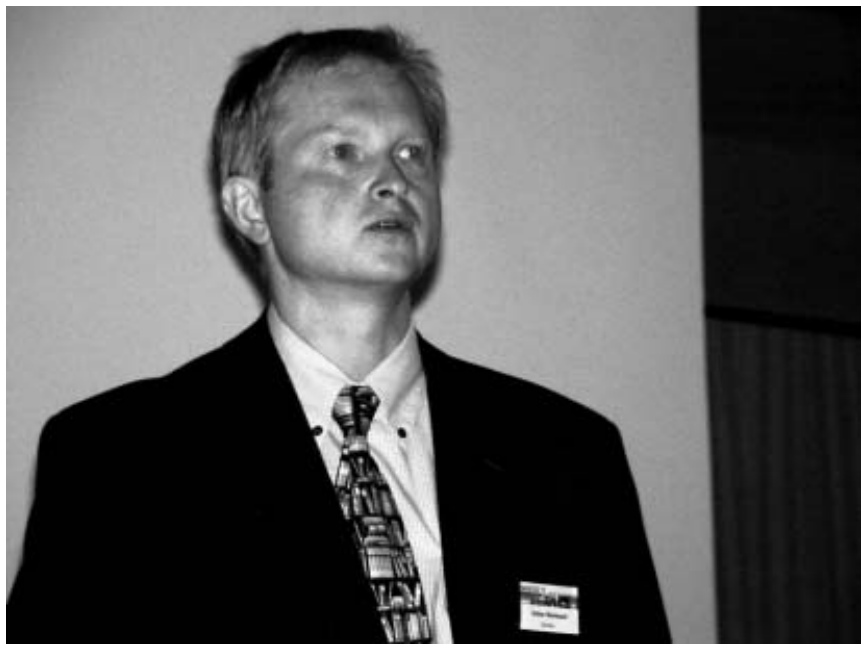

Dr. Volker Steinbach (AEGS Vice-President) welcomes the participants of MAEGS-13 to Hanover. other disciplines working towards implementing what is perhaps the most far-reaching continent-wide hydrological plan ever conceived. Opening the conference, Dr Steinbach stressed the importance of transnational cooperation in hydrology and hydrogeology, since neither water nor rocks were any respecters of political boundaries.

The main meeting began after a day of workshops dedicated to hydrogeological mapping for the Water Framework Directive (WFD), including the "International Hydrogeological Map of Europe at 1:15,000,000", and demonstrations of a new Map Server Application for the hydrogeological survey map of Germany. Papers presented over the following two days covered aspects of implementing the WFD in different European countries; various case-studies describing the all-important characterization of groundwater bodies; the interaction between groundwater and surface water and the implications of this for river basin management; and case studies illustrating various aspects of quality assessment around diffuse and point sources of contamination.

The oncoming meeting (MAEGS-14), to be held in Turin in September 2005, will continue the AEGS's strategy of treating geoscience subjects relevant to trans-European cooperation and societal needs - if possible in an area that provides good examples, to give added relevance to the accompanying field excursions. Under the chair of Prof. Francesco Carraro (AEGS president) and Dr. Marco Giardino (secretary of the Organizing Committee), the oncoming MAEGS-14 "Natural hazards related to recent geological processes" will concentrate on geohazards that arise as a consequence of longer-term geological trends - something familiar to those who live among the active tectonics of the Alps, Apennines and Po valley. Thereafter it is planed to organize MAEGS-15 in Tallinn (Estonia), under the chair of Dr. Rein Raudsep from the Estonian Geological Survey.

\section{History}

The origins of AEGS are embodied in a printed letter in both English and French of Sir Kingsley Dunham of June 1974 which was widely circulated throughout Europe. This accompanied the First Circular announcing the $1^{\text {st }}$ Meeting of the European Geological Societies

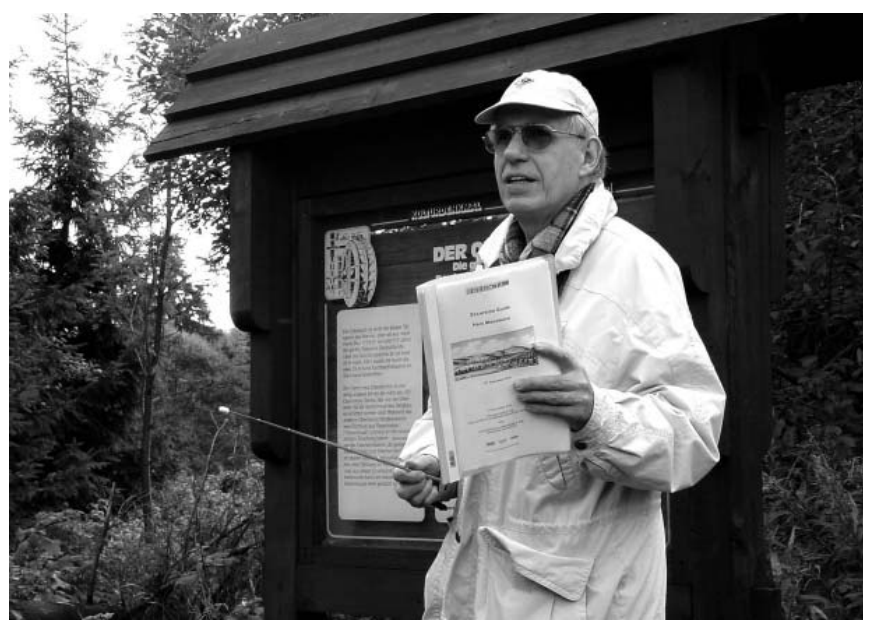

Dr. Friedrich-Wilhelm Wellmer (President German Geological Society and German Geological Survey) leads a field excursion to the Harz Mountains. 
(MEGS), under Sir Kingsley Dunham's Presidency, with the theme "Europe - from Crust to Core" which was held at Reading in the UK September 1975.

A Bridging Committee for the future organisation of MEGS was established in 1975 under Dr. J. V. Hepworth's Chairmanship. MEGS-2 was held at the Free University of Amsterdam May 1978 with the theme "Europe - Basins and Source Areas". The Bridging Committee endeavoured to establish a European Geological Association to achieve continuity of MEGS and draft statutes to the end of
Jens Wiegand (AEGS Secretary)

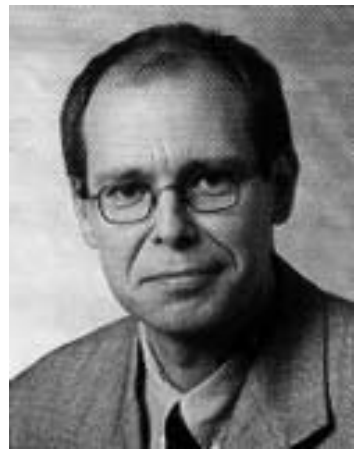

MEGS-2 which were adopted at Amsterdam on $11^{\text {th }}$ May 1978. It was hoped to formalise the constitution of the European Geological Association (EGA) during the Paris meeting of the International Geological Congress in the summer of 1980.

The two following meetings were held in Erlangen, Germany in the beginning of June 1982 under the theme "Europe on the Geological Map" (MEGS-3), and in Edinburgh, Scotland April 1985 to coincide with the $150^{\text {th }}$ Anniversary of the Edinburgh Geological Society with the theme "The Evolution of the European Lithosphere" (MEGS-4).

The "Association of European Societies" (AEGS) was formed on 9 October 1987 in Dubrovnik, Yugoslavia during MAEGS-5 under the theme "Orogeny, Magmatism and Metallogeny in Europe". Since 1988 AEGS has the status of an Affiliated Organisation of the IUGS.

Thereafter, meetings were held in the following order:

- MAEGS-6: Lisbon, Portugal - October 1990, “The Atlantic and its Relation to Europe".

- MAEGS-7: Paris, France - September 1991, "Seismic and Drillhole Investigation of the European Crust"

- MAEGS-8: Budapest, Hungary - September 1993, "Evolution of Intramontane Basins on the Example of the Pannonian Basin with Particular Emphasis on the Sequence Stratigraphy and Neotectonics"

- MAEGS-9: St. Petersburg - Russian Federation - September 1995, "Precambrian of Europe, Stratigraphy, Structure, Evolution and Mineralization"

- MAEGS-10: Carlsbad, Czech Republic - September 1997, "Challenges to Chemical Geology"

- MAEGS-11: Alicante, Spain - September 1999, "European paleogeography and geodynamics: a multidisciplinary approach"
- MAEGS-12: Cracow, Poland - September 2001, "Carpathian paleogeography and geodynamics"

In consideration of the $25^{\text {th }}$ anniversary of AEGS (1975-2000), the Chronicle of AEGS had been published (Dudich 2001).

\section{Members}

Societies of the following countries are represented in the AEGS: Members of the Geological Societies of Albania, Austria, Belgium, Bulgaria, Croatia, Czech Republic, Denmark, Estonia, Finland, France, Germany, Greece, Hungary, Italy, Latvia, Lithuania, Macedonia, Netherlands, Norway, Poland, Portugal, Romania, Russia, Serbia, Slovakia, Spain, Switzerland, Ukraine, United Kingdom.

\section{Executive Board}

The steering committee of AEGS consists out of 14 members. The current president is the chairman of the oncoming meeting: Prof. Dr. Francesco Carraro (University of Torino, Italy). The vice-president organised the last meeting: Dr. Volker Steinbach (BGR, Germany). The secretary position is hold by PD Dr. Jens Wiegand (University of Duisburg — Essen, Germany) since 1997.

\section{More information}

If you want to have additional information about AEGS, please visit the homepage: www.aegs.de or contact the secretary of AEGS: PD Dr. Jens Wiegand, University of Duisburg-Essen, Department 9 Geology, Universitaetsstrasse, 45141 Essen, Germany.

Priv. -Doz. Dr. Jens Wiegand

Universitäet Duisburg - Essen

Fachbereich 9 - Geologie

Universitäetsstrasse

45117 Essen

GERMANY

Tel: national: (0201) 1833103

international: $+49-2-1-1833103$

Fax: national: (0201) 1833101

international: $+49-201-1833101$

E-mail: jens.wiegand@uni-essen.de 